EESTI NSV TEADUSTE AKADEEMIA TOIMETISED. KEEMIA

ИЗВЕСТИЯ АКАДЕМИИ НАУК ЭСТОНСКОЙ ССР. ХИМИЯ

PROCEEDINGS OF THE ACADEMY OF SCIENCES OF THE ESTONIAN SSR CHIEMISTRY

$1985,34,3$

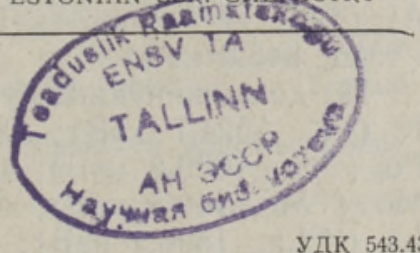

Л. ПЕЛЕКИС, Зане ПЕЛЕКИС, И. ТАУРЕ,

О. КИРРЕТ, Э. РАЯВЕЕ

\title{
ИНСТРУМЕНТАЛЬНЫЙ НЕЙТРОННО-АКТИВАЦИОННЫЙ АНАЛИЗ ДИКТИОНЕМОВОГО СЛАНЦА МААРДУСКОГО МЕСТОРОЖДЕНИЯ
}

Исследования геологии, химического и минералогического состава, а также различных свойств диктионемового сланца, начатые в конце XVIII столетия, продолжают оставаться объектами внимания многих ученых по сей день $\left[{ }^{1-9}\right]$. В первой половине XIX века известный химик И. Я. Берцелиус изучал свойства и термолиз шведского сланца (Alaunschiefer, alum shale), который по геологическому возрасту и химическому составу довольно близок диктионемовому $\left[^{10}\right]$. Сведения о содержании отдельных микроэлементов и элементов-примесей в диктионемовом сланце опубликованы в целом ряде работ [11-21]. Однако для оценки относительной достоверности приводимых там фактических данных весьма важно знать, какой метод определения элементов при этом использовался, а об этом упоминается далеко не во всех статьях. Поэтому выбор правильной методики при исследовании материала столь сложного состава имеет очень важное значение.

Диктионемовый сланец месторождения Маарду изучался нами инструментальным нейтронно-активационным методом на ядерном реакторе с плотностью потока $(1-3) \cdot 10^{13}$ нейтрон $/ \mathrm{cm}^{2} \cdot$ с в Институте физики АН Латвийской ССР. Среднюю пробу сланца в виде мелкого порошка активировали в вертикальных экспериментальных каналах реактора и на установке нейтронно-активационного анализа по короткоживущим нуклидам на горизонтальном канале реактора.

Для облучения в вертикальных каналах пробы массой 50-100 мг упаковывали в конвертики из алюминиевой фольги и вместе с эталоном помещали в алюминиевые контейнеры. При использовании установки на горизонтальном канале пробы массой $15-25$ мг упаковывали в конвертики из полиэтиленовой пленки толщиной 0,05 мм и помещали в специальные полиэтиленовые ампулы для пневмотранспортировки. Использовали одно- и многоэлементные эталоны. Первые готовили из растворов металлов и их солей, многократно разбавляя до нужных концентраций. В качестве вторых использовали синтетические стандарты на базе фенолформальдегидной резольной смолы, изготовленные в Институте физики Грузинской ССР, и эталонный материал MAГАTЭ-SOIL-5.

Время облучения в вертикальных каналах составляло 70 ч. Через трое суток остывшие образцы и эталоны вновь упаковывали в чистые полиэтиленовые мешочки. Для анализа по короткоживущим. нуклидам образцы и эталоны поочередно облучали в течение $30 \mathrm{c}$.

Гамма-спектры измеряли на полупроводниковых $\mathrm{Ge}(\mathrm{Li})$-спектрометрах с 1024-канальными анализаторами несколько раз после разных времен ожидания. 
По короткоживущим нуклидам определены: $\mathrm{Na}$ (по ${ }^{24} \mathrm{Na}$, аналитическая гамма-линия с энергией 1368,5 кэВ); $\mathrm{Mg}\left({ }^{27} \mathrm{Mg}, 1014,4\right.$ кэВ); $\mathrm{Al}\left({ }^{28} \mathrm{Al}, 1778,8\right.$ кэB $) ; \mathrm{Ti} \quad\left({ }^{51} \mathrm{Ti}, 320,1\right.$ кэB $) ; \mathrm{V}\left({ }^{52} \mathrm{~V}, 1434,4\right.$ кэB $) ; \mathrm{Mn}$ $\left({ }^{56} \mathrm{Mn}, 846,8\right.$ кэВ).

По долгоживущим нуклидам определены:

$\mathrm{K}\left({ }^{42} \mathrm{~K}, 1524,7\right.$ кэB $) ; \quad \mathrm{Sc}\left({ }^{46} \mathrm{Sc}, 1120,5\right.$ кэВ $) ; \quad \mathrm{Cr}\left({ }^{51} \mathrm{Cr}, 320,1\right.$ кэВ $)$; Fe $\left({ }^{59} \mathrm{Fe}, 1099,2\right.$ кэB $)$; Co $\left({ }^{60} \mathrm{Co}, 1332,5\right.$ кэB $)$; Rb $\left({ }^{86} \mathrm{Rb}, 1078,7\right.$ кэB $)$; Мо ( ${ }^{99} \mathrm{Mo}, 140,5$ кэВ); $\mathrm{Sb}\left({ }^{124} \mathrm{Sb}, 1691,0\right.$ кэВ $) ; \quad \mathrm{Ba}\left({ }^{131} \mathrm{Ba}, 124\right.$ кэВ); $\mathrm{La}\left({ }^{140} \mathrm{La}, 1596,2\right.$ кэВ $) ; \mathrm{Ce}\left({ }^{141} \mathrm{Ce}, 145,0\right.$ кэВ $) ; \mathrm{Tb}\left({ }^{160} \mathrm{~Tb}, 966,2\right.$ кэВ); $\mathrm{Br}\left({ }^{82} \mathrm{Br}, 776,5\right.$ кэB $) ; \quad \mathrm{Sm}\left({ }^{153} \mathrm{Sm}, 103,2\right.$ кэ $\left.\mathrm{B}\right) ; \mathrm{Eu}\left({ }^{152} \mathrm{Eu}, 1408\right.$ кэB $)$; $\mathrm{Lu}\left({ }^{177} \mathrm{Lu}, 208,4\right.$ кэB $) ; \quad \mathrm{Yb}\left({ }^{169} \mathrm{Yb}, 197,9\right.$ кэB $) ; \quad \mathrm{Hf}\left({ }^{181} \mathrm{Hf}, 482,4\right.$ кэB $)$; Та $\left({ }^{182} \mathrm{Ta}, 1189,0\right.$ кэВ); $\mathrm{Au}\left({ }^{198} \mathrm{Au}, 411,8\right.$ кэВ).

Содержание элементов рассчитывали относительным методом, сравнивая число импульсов в фотопиках аналитических гамма-линий проб и эталонов. При необходимости оценивали и вводили поправки на конкурирующие реакции и эффект самоэкранировки. Результаты анализа получали суммированием 3-8 параллельных определений. Относительное стандартное отклонение составляло $3-7 \%$.

В составе диктионемового сланца удалось выявить 29 макро- и микроэлементов, а также элементов-примесей. Концентрации для 27 из них приведены в таблице. Отметим, что если определение макроэлементов в весьма сложных по составу природных минералах классическими методами количественного анализа не представляет трудностей, то установление в них достоверных концентраций микроэлементов и элементов-примесей немыслимо без привлечения новейших инструментальных методов (нейтронно-активационного, атомно-абсорбционного, различных спектральных и т. д.). Нами определены концентрации семи лантаноидов ( $\mathrm{La}, \mathrm{Ce}, \mathrm{Tb}, \mathrm{Yb}, \mathrm{Sm}, \mathrm{Eu}, \mathrm{Lu})$ и некоторых других редких элементов (напр., Sc, Rb, Hf и Тa), большинство из которых ранее не были известны в качестве компонентов этога минерала.

Результаты инструментального нейтронно-активационного анализа образца диктионемового сланца

\begin{tabular}{l|c||c|c}
\hline Элемент & $\begin{array}{c}\text { Содержание, r/r образца } \\
\text { (средняя проба) }\end{array}$ & Элемент & $\begin{array}{c}\text { Содержание, r/r образца } \\
\text { (средняя проба) }\end{array}$ \\
\hline & $1,0 \times 10^{-2}$ & & \\
$\mathrm{Mg}$ & $4,1 \times 10^{-2}$ & $\mathrm{Cr}$ & $6,5 \times 10^{-5}$ \\
$\mathrm{Fe}$ & $6,1 \times 10^{-2}$ & $\mathrm{Ce}$ & $7,4 \times 10^{-5}$ \\
$\mathrm{~K}$ & $9,1 \times 10^{-2}$ & $\mathrm{Ta}$ & $8,4 \times 10^{-5}$ \\
$\mathrm{Al}$ & $0,9 \times 10^{-3}$ & $\mathrm{~Tb}$ & $0,2 \times 10^{-6}$ \\
$\mathrm{Na}$ & $1,2 \times 10^{-3}$ & $\mathrm{Lu}$ & $0,4 \times 10^{-6}$ \\
$\mathrm{Mn}$ & $2,8 \times 10^{-3}$ & $\mathrm{Hf}$ & $1,2 \times 10^{-6}$ \\
$\mathrm{Cl}$ & $5,4 \times 10^{-3}$ & $\mathrm{Yb}$ & $2,1 \times 10^{-6}$ \\
$\mathrm{Ti}$ & $2,1 \times 10^{-4}$ & $\mathrm{Br}$ & $2,2 \times 10^{-6}$ \\
$\mathrm{Rb}$ & $3,3 \times 10^{-4}$ & $\mathrm{Sm}$ & $4,2 \times 10^{-6}$ \\
$\mathrm{Ba}$ & $4,7 \times 10^{-4}$ & $\mathrm{Sb}$ & $4,6 \times 10^{-6}$ \\
$\mathrm{~V}$ & $1,2 \times 10^{-5}$ & $\mathrm{Eu}$ & $4,7 \times 10^{-6}$ \\
$\mathrm{Co}$ & $1,5 \times 10^{-5}$ & $\mathrm{Au}$ & $9,4 \times 10^{-7}$ \\
$\mathrm{Sc}$ & $3,7 \times 10^{-5}$ & & \\
$\mathrm{La}$ & & &
\end{tabular}

Можно предположить, что возможности нейтронно-активационного метода еще далеко не исчерпаны настоящим исследованием и круг пока не выявленных элементов диктионемового сланца будет в дальнейшем расширен. В частности, в его составе, как осадочной породы морского происхождения, следует ожидать наличия иода.

Авторы статьи из АН Эстонской ССР глубоко признательны руководству Института физики АН Латвийской ССР за предоставленную возможность проведения данной работы. 


\section{ЛИТ Е РА Т УРА}

1. Georgi, I. Von einer feuerfangenden Erde aus der Revalschen Stadthalterschaft. - In: Auswahl ökonomischer Abhandlungen, 3. St. Petersburg, 1791, 330-331.

2. Гельмерсен $\Gamma$. О месторождении смолистого сланца и вновь открытом горючем материале в переходной формации Эстляндской губернии. - Горный журнал, 1839, III, 149-157.

3. Kuppfer, A. Uber die chemische Constitution der baltisch-silurischen Schichten. Archiv für Naturkunde des Liv-, Est- und Kurlands, I Ser., V. Dorpat, 1870, 69-194.

4. Rägo, N. Beiträge zur Kenntnis des estlandischen Dictyonemaschiefers. - Tartu Ulikooli toim., 1928, Seeria A, XIII.

5. Сийрде A. K. Некоторые новые данные о диктионемовом сланце. - Тр. Таллин политехн. ин-та, 1956, вып. III, сер. А, № 73, 3-22.

6. Kirret, O., Gerassimov, N., Tikk, A. Diktüoneema kiltkivi termilisest lagundamisest. - Teaduslik-tehniline kogumik, 10. Tln., 1948, 47-59.

7. Киррет О. Г., Поликарпов Н. К., Луцковская Н. Л., Валдек Р. Г., Эйзен Ю. И. О составе и свойствах диктионемового сланца месторождения Маарду ЭССР. - Изв. АН ЭССР. Сер. техн. и физ.-матем. Н., 1957, VI, № 2, $170-183$.

8. Kirret, O., Koch, R., Ründal, L. Maardu leiukoha diktüoneemakilda ja temas sisalduva kerogeeni keemilisest koostisest. - ENSV TA Toim. Tehn. ja füüs.-matem. tead. seeria, 1959, VIII, nr. 4, 243-255.

9. Кордиков А. А. Минералогическая характеристика диктионемовых сланцев Маардуского месторождения. - Изв. АН ЭССР. Сер. физ.-матем. и техн. н., 1962, XII, № 1, 67-72.

10. Berzelius, J. J. Lehrbuch der Chemie. Achter Band. Dresden, Leipzig, 1839, 473-474, $655-656$.

11. Rankama, K., Sahama, Th. G. Geochemistry. Chicago, 1955, 638.

12. Альтгаузен М., Маремяэ Э., Ноханнес Э., Липпмаа Э. Гипергенное разложение черных металлоносных сланцев. - Йзв. АН ЭССР. Хим., 1980, 29, №2 3, $165-169$.

13. Пальмре X. Заметки о встречаемости индия в пиритовых криста̇ллах палеозойских отложений Эстойской ССР. - Изв. АН ЭССР. Хим. Геол., 1976, 25, № $3,245-247$.

14. Пальмре X., Хедреярв $X$. Заметки о встречаемости молибдена и рения в пиритовых кристаллах палеозойских отложений Эстонии. - Изв. АН ЭССР. Хим., 1980, 29, № 1, 49-51.

15. Кох Р., Кийс K. О некоторых особенностях процесса термолиза органического вещества аргиллита - диктионемового сланца Маардуского месторождения. 1. Выход продуктов термолиза. - Изв. АН ӘССР. Хим., 1983, 32, № 1, $8-18$.

16. Клаос-Хачатурян E., Талькоп P., Одинец В. Подготовка проб аргиллитов для атомно-абсорбционного анализа. - Изв. АН ЭССР. Хим., 1983, 32, № 2, $109-113$.

17. Палвадре Р., Утсал К., Ахелик В., Халдна Ю. Исследование минерального состава граптолитового аргиллита Эстонии. - Горючие сланщы, 1984, I/2, 162-170.

18. Палвадре P., Лоог А., Халдна Ю., Ахелик В., Талькоп Р. Корреляционные связн между компонентами в граптолитовых аргиллитах Эстонин. - Горючие сланцы, 1984, I/3, 292-300.

19. Пелекис З. Э., Пелекис Л. Л., Тауре И. Я., Липпмаа Э. Т., Маремяэ Э. Я., Пихлак А. А. Инструментальное нейтронно-активационное определение состава проб фосфоритовых руд, диктионемовых сланцев и других природных объектов Эстонской ССР. - Изв. АН ЛатвССР. Сер. физ. и техн. н., 1984, № 1, 3-8.

20. Нванов В. В., Поплавко Е. М., Тимофеева О. С. Особенности распределения элементов-примесей в углеродистых сланцах Эстонии. - Геохимия, 1984, № 6, 903-912.

21. Пихлак А. О склонности диктионемовых сланцев из месторождений фосфоритов Эстонской ССР к самовозгоранию. - Горючие сланцы, 1984, I/3, 259.

Институт физики
Академии наук Латвийской ССР

Поступила в редакцию

Институт химии

Академии наук Эстонской ССР

11/III 1985 
L. PELEKIS, Zane PELEKIS, I. TAURE,

O. KIRRET, E. RAJAVEE

- MAARDU LEIUKOHA DIKTUONEEMAKILDA INSTRUMENTAALNE NEUTRONAKTIVATSIOONIANALUUS

Instrumentaalse neutronaktivatsioonianalüüsi abil on määratud Maardu leiukoha diktüoneemakilda proovis seitse lantanoidi ( $\mathrm{La}, \mathrm{Ce}, \mathrm{Tb}, \mathrm{Yb}, \mathrm{Sm}, \mathrm{Eu}, \mathrm{Lu})$ ning möned haruldased elemendid, näiteks Sc, Rb, Hf ja Ta.

L. PELEKIS, Zane PELEKIS, I. TAURE,

O. KIRRET, E. RAJAVEE

\section{INSTRUMENTAL NEUTRON ACTIVATION ANALYSIS OF ALUM SHALE FROM} THE MAARDU DEPOSIT

Seven lantanoids ( $\mathrm{La}, \mathrm{Ce}, \mathrm{Tb}, \mathrm{Yb}, \mathrm{Sm}, \mathrm{Eu}, \mathrm{Lu}$ ) and some other rare elements (for example, Sc, Rb, Hf, Ta) were obtained in the alum shale from the Maardu deposit using instrumental neutron activation method. 